\title{
Keep standards high
}

\section{As models of authorship and collaboration change in the digital age, we must rely on trust to filter the products of research, says Jerome Ravetz.}

S cience is unique among areas of organized activity and production in that it has an informal quality-assurance system: peer review, publication and replication. The system has worked well since its inception in the seventeenth century, when the scientific journal came into being. But it is now being challenged as technology changes social practices of science. How might it evolve?

Some trends are apparent. The rise of digital media has revolutionized the management of information and created opportunities for broader involvement in science's production. Collaborations are growing ever larger, transforming the concept of authorship. Prepublication discussions of research on blogs dilute a principal author's claim to discovery. And the public is increasingly involved.

Amateurs are returning to mainstream research after an absence of generations. By completing online tasks, from classifying galaxies (http://galaxyzoo. org) to solving complex protein-folding problems (http://folding.stanford.edu), anyone can become a co-creator of scientific knowledge. Such a widening of participation might be liberating, but it also risks lowering standards. Not everyone shares the ideal that intellectual integrity comes before personal gain.

As a result of these developments, the product of research is becoming more fluid. The journal is losing its status as the sole gatekeeper - simultaneous guarantor of quality, certifier of property, medium of communication and also archive. Other means of sharing material, assessing quality and screening out the incompetent or fraudulent are emerging to fill the gap, but ultimately the professional monopoly on quality assurance of science will have to be modified.

\section{NEW GATEKEEPERS}

In response to these trends, some individuals are becoming self-appointed gatekeepers. During the polarized 'climategate' debates in 2010, for example, climate scientists stepped in to defend the work of a reputable colleague from criticism by a 'mere' mining engineer. That critic, Steve McIntyre, claimed on his blog simply to be applying the standards of the business world to climate data.

Although scientific expertise presents a bar to interference, concerned outsiders have a legitimate and useful role. The setting of policy priorities is one such example. Institutions such as the Cochrane Collaboration employ thousands of 'expert patients' across the globe to review the quality of research papers on treatments.

Whistle-blowing is another vital form of intervention. As technological advances bring new perils, people can provide early warnings that prevent real harm. Here, the blogosphere holds great promise for free information sharing. But with its lack of

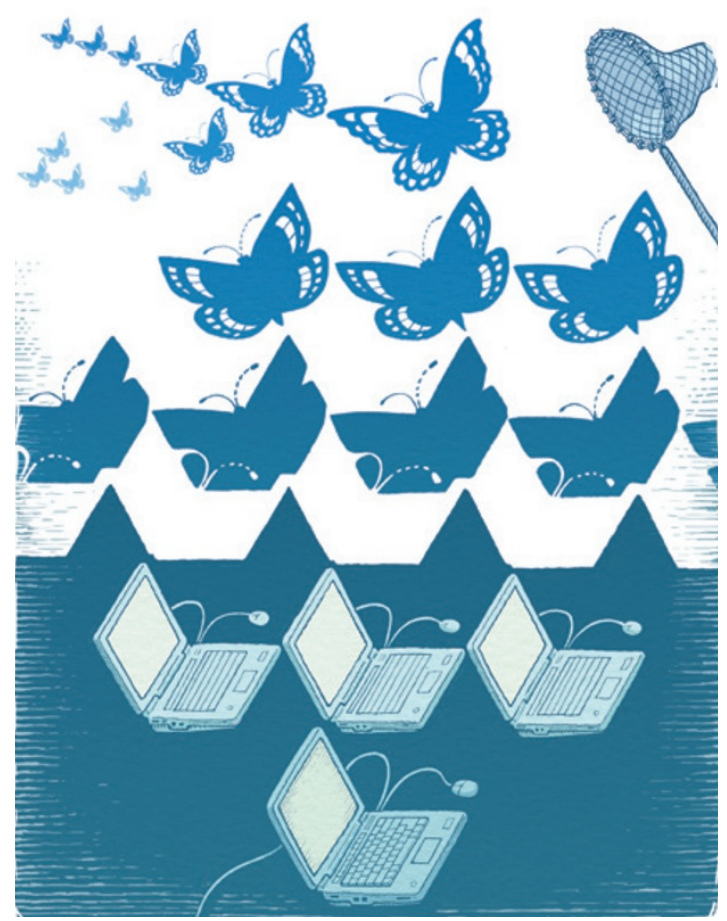

formal quality assurance, some see it as a possible vehicle for a scientific demagogue like Soviet biologist Trofim Lysenko.

In some circles, gatekeepers are being done away with. Many high-technology sectors already operate along communitarian lines. For example, 'open source' and 'creative commons' enterprises handle intellectual property collaboratively. Signatories publish their specifications freely, allowing others to copy and adapt the work, as long as people credit it and there is mutual access to ideas. These sound like the ideals of science as based on the work of US sociologist Robert Merton: communalism, universalism, disinterestedness, originality and scepticism.
It would be ironic but welcome if the technology sector, traditionally managed through the private-property system of patents, were to lead the way in open science. Within a more informal system, the current excessively quantitative systems of qualityassessment - the numbers of papers and citations - could be relaxed and made more personal and communal. Quality assurance could be achieved by a societal consensus and professional gatekeepers.

For this to happen, barriers to sharing scientific information with the public, such as journal paywalls, should come down. And better online discussion forums must be developed. The presentation and archiving of blogs and other forms of internet communications should be improved, so that ideas can be debated and added to over time.

As more people become involved in online debates, quality need not fall by the wayside. It is encouraging to see that well-conducted discussions of points of contention between the scientific mainstream and critics are emerging, as the Berkeley Earth Surface Temperature study demonstrates (see Nature 478, 428; 2011).

Ultimately, effective quality assurance depends on trust. And science relies on trust more than most institutions. As Steven Shapin, a historian of science at Harvard University in Cambridge, Massachusetts, showed in his 1994 book $A$ Social History of Truth, trust is achieved and maintained only by mutual respect and civility of discourse. In a digital age, civility should be extended to, and reciprocated by, the extended peer community.

Scientists have a special responsibility, but also a special difficulty. When their training has been restricted to puzzles with just one right answer, scientists may find it hard to comprehend honest error, and may condemn those who persist in apparently wrong beliefs. But amid all the uncertainties of science in the digital age, if quality assurance is to be effective, this lesson of civility will need to be learned by us all.

Jerome Ravetz is at the Institute for Science, Innovation and Society at the University of Oxford, Oxford OX1 1HP, UK. He is the author of Scientific Knowledge and its Social Problems $(1971,1996)$.

e-mail:jerome-ravetz@ntlworld.com 